\title{
Radiological assessment of chest compression point and achievable compression depth in cardiac patients
}

\author{
Sverre Nestaas ${ }^{1 *}$, Knut Haakon Stensæth ${ }^{2}$, Vigdis Rosseland ${ }^{3}$ and Jo Kramer-Johansen ${ }^{1,4}$
}

\begin{abstract}
Background: Using magnetic resonance imaging (MRI) to relate cardiovascular structures to surface anatomy in a population relevant to cardiac arrest victims, relate the external thoracic anterior-posterior (AP) diameter (AP EXTERNAL) and blood-filled structures to recommended chest compression depths, and define an optimal compression point (OCP).

Methods: MRI axial scans of referred patients were analysed. We defined origo as the skin surface of the centre of sternum in the internipple line. The blood-filled structures beneath origo were identified and the sum of their inner diameters $\left(A P_{B L O O D}\right)$ and $A P_{\text {EXTERNAL }}$ were measured. We defined OCP based on the image with maximum compressible left and right ventricle and where LVOT was not present. We measured the distance from origo to OCP.

Results: Consecutive patients, mean (SD), age 52 (17) years, 110 (76\%) males, were categorized: cardiac disease $(n=74)$, aortic disease $(n=13)$, no findings/study patient (included in another study) $(n=57)$. The structure LVOT/aortic valve (AV/aortic root was present in $46 \%$ of patients with cardiac disease vs. $19 \%$ of patients with no findings. AP EXTERNAL for males and females was $25(2) \mathrm{cm}$ and $22(2) \mathrm{cm}$, and $A P_{B L O O D} 6.5 \mathrm{~cm}$ (2) and $4.7 \mathrm{~cm}$ (2), respectively. Distance from origo to OCP was 32 (11) $\mathrm{mm}$ to the left and 16 (21) mm caudally.

Discussion: LVOT/AV/aortic root was present beneath the origo in almost half the patients with cardiac disease. Recommended chest compression depths exceeded the anterior-posterior diameter of blood-filled structures in more than half of the females. OCP was found $3 \mathrm{~cm}$ left of the origo.

Conclusions: Based on our study, individualized compression point and depth could be further studied in a prospective, clinical study.

Keywords: Cardiopulmonary resuscitation, Chest compression, Hand position, Anatomical landmark, Compression depth, Magnetic resonance imaging (MRI)
\end{abstract}

\section{Background}

Effectiveness of chest compressions during cardiopulmonary resuscitation (CPR) can be altered by hand position and compression depth, among other components [1]. The International Liaison Committee on Resuscitation (ILCOR) recommends placing the hands on the lower half of the sternum and concluded in 2010 that the use of the internipple line (INL) as a landmark for hand placement is not reliable $[1,2]$. However, there is little scientific evidence

\footnotetext{
* Correspondence: nestaas@gmail.com

${ }^{1}$ Department of Anaesthesiology, Oslo University Hospital, Po Box 4956

Nydalen, N-0424 Oslo, Norway

Full list of author information is available at the end of the article
}

regarding the optimum hand position for chest compressions and the INL is an easily detectible surface landmark. Altered hand position might change compression of intrathoracic structures. Forward blood flow during CPR is provided by compression of the heart (cardiac pump theory) and/or intra-thoracic pressure fluctuations (thoracic pump theory). According to the cardiac pump theory, direct compression of the ventricles is important. Previous CT studies have however shown that rather than the left ventricle, structures beneath the INL have been the ascending aorta, the root of aorta, or the left ventricular outflow tract (LVOT) [3]. Compression of the base of the heart or the LVOT might impede forward blood 
flow $[4,5]$, whereas compression of both ventricles avoiding LVOT might be more effective. As to compression depths, European Resuscitation Council (ERC) decided in 2015 to retain the 2010 guidance that chest compressions should be at least $5 \mathrm{~cm}$ but not more than $6 \mathrm{~cm} \mathrm{[6],} \mathrm{which} \mathrm{equates} \mathrm{to} \mathrm{approximately} \mathrm{one-fifth}$ of the adult chest [7]. The ERC recommendations are regardless of gender, body size, and medical history.

The purpose of this study was to establish how cardiovascular structures known to affect CPR, relate to surface anatomy in patients referred to cardiac magnetic resonance imaging (MRI). We then related the external anteriorposterior (AP) diameter of both the thorax and of its blood-filled structures, to the recommended chest compression depths. Finally, we defined a hypothesis generating optimal compression point (OCP) based on maximum compressible left and right ventricle.

\section{Methods}

\section{Setting and participants}

This was a prospective observational study of consecutive patients aged 16 and above referred to cardiovascular MRI (CMR) between January 2012 and June 2013. The MRI scans included evaluation of suspected or manifest diseases such as ischaemic heart disease, non-ischaemic heart disease (mainly hypertrophic/dilated cardiomyopathy, myocarditis, and arrhythmogenic right ventricular cardiomyopathy (ARVC)), aortic diseases, and patients taking part in other cardiovascular MRI studies (study patients). Demographic data was collected and patients categorized into three clinical groups based on the conclusions from the CMR radiologist: Cardiac disease, aortic disease or no findings/study patient. The regional ethical board approved the study (REK 2011/748) and participants gave their written consent. Patients received neither compensation nor benefits from participation in the study.

\section{MRI scan}

We used 1.5 T MRI scanners (Philips Achieva/Philips NT Intera, Philips Healthcare, Best, the Netherlands) for all MRI examinations. Patients were lying supine with the arms along their sides, and held their breath during the scan. To facilitate surface landmark identification, five fish oil softgels were placed along the INL. Fish oil softgels consist mainly of fat and are easily detectable on MRI without causing artifacts. Only the survey images, consisting of 8-10 $\mathrm{mm}$ axial scans used for planning the remaining MRI exam, were used in our study. All MRI images were anonymized before export and analysis.

\section{Measurements}

We defined the axial survey image with the fish oil softgels as the INL image, and defined origo as the skin surface above the centre of sternum in this image (Fig. 1a). The

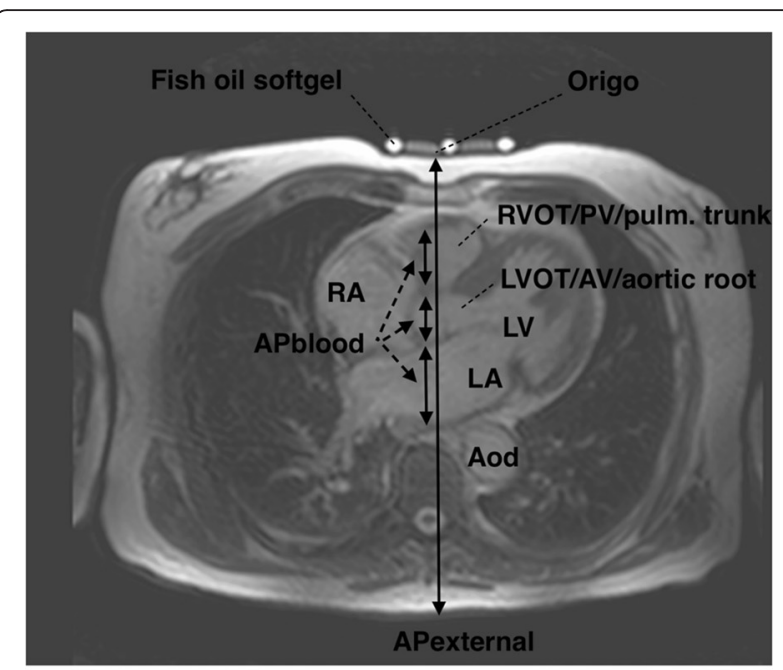

a

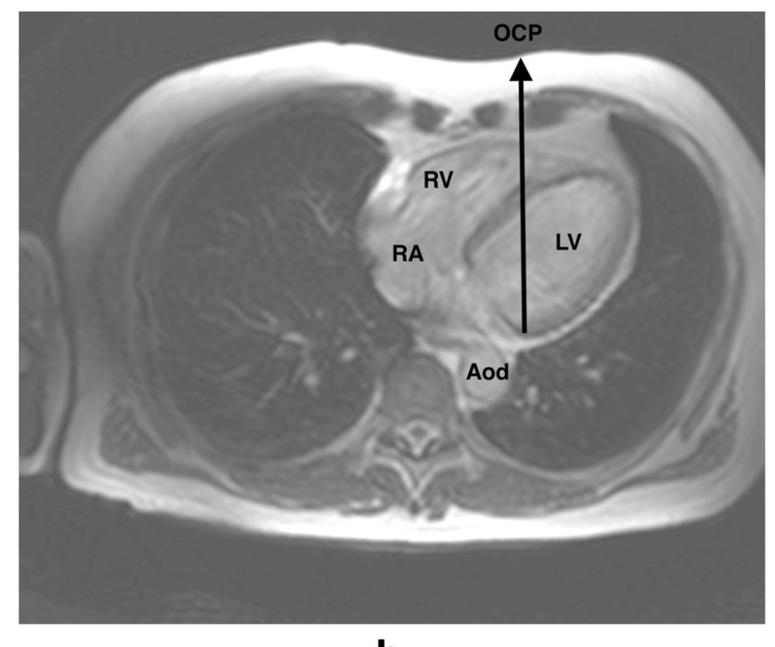

b

Fig. 1 a The internipple line (INL) image showing APEXTERNAL and $\mathrm{AP}_{\mathrm{BLOOD}}$ (the sum of blood-filled structures along $A P_{\text {EXTERNAL.) Fish }}$ oil softgels identify the INL level. Abbreviations: Aod, descending aorta; $\mathrm{AP}_{\mathrm{BLOOD}}$, Anterior-posterior diameter of blood-filled structures;

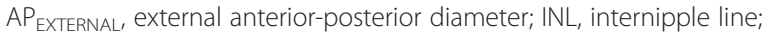
$L A$, left atrium; $L V$, left ventricle; LVOT/AV/aortic root, left ventricular outflow tract/aortic valve/aortic root; Origo, centre of sternum at the level of the INL; RA, right atrium; RVOT/PV/pulmonary trunk, right ventricular outflow tract/pulmonary valve/pulmonary trunk. b Optimal compression point (OCP) image showing how OCP was identified. OCP is the surface projection of a line with maximum sum of left and right ventricle AP diameters. Abbreviations: Aod, descending aorta; LV, left ventricle; OCP, optimal compression point; $\mathrm{RA}$, right atrium; RV, right ventricle

external $\mathrm{AP}$ diameter $\left(\mathrm{AP}_{\text {EXTERNAL }}\right)$ was perpendicular to the skin and represented the distance between origo and the skin dorsally. The left ventricular outflow tract (LVOT), aortic valve (AV), and aortic root are anatomically closely related, and were therefore joined in a common anatomical structure called LVOT/AV/aortic root. The right ventricular outflow tract (RVOT), pulmonary valve (PV), and 
pulmonary trunk were joined in the anatomical structure RVOT/PV/pulmonary trunk for the same reason. We identified the dominating structure as the structure with the largest AP diameter in both the INL image and the adjacent images caudal and cephalad combined. Further, in each patient, we quantified the inner diameters of the intrathoracic blood-filled structures along the $\mathrm{AP}_{\text {EXTERNAL }}$ in the INL image (Fig. 1a). The sum of the inner diameters was called the AP diameter of blood-filled structures $\left(\mathrm{AP} P_{\mathrm{BLOOD}}\right)$. We calculated the ratio between $\mathrm{AP}_{\mathrm{BLOOD}}$ and AP EXTERNAL.

Finally, we defined a hypothesis generating optimal compression point $(\mathrm{OCP})$ as the ventral skin surface projection of a line perpendicular to the skin dorsally (Fig. 1b) in the axial image where LVOT was not present, and where the sum of left and right ventricle AP diameters was as large as possible. We defined this image as the OCP image. The distance from the origo (INL image) to the OCP (OCP image) in the coronal plane was calculated using coordinates provided by Osirix software. All measurements were done by one of the authors $(\mathrm{SN})$ using OsiriX software (v.5.9 32-bit by Pixmeo SARL, Bernex, Switzerland). An experienced CMR radiologist (KHS) performed review of $56 \%$ of the cases, based on the initial registrations and measurements.

\section{Statistical analysis}

All variables are reported as mean (SD) or median (IQR), as appropriate based on normality tests and compared using Student's $t$-test or Mann-Whitney $U$-test accordingly for continuous data, and Chi-squared tests with continuity correction for categorical data. We performed multiple regression analyses of the dependent variables; $\mathrm{AP}_{\text {EXTERNAL, }} \mathrm{AP}_{\mathrm{BLOOD}}$, and the $\mathrm{AP}_{\mathrm{BLOOD}} /$ $\mathrm{AP}_{\text {EXTERNAL }}$-ratio to find possible explanatory factors in gender (male, female), age (continuous), height (continuous), and clinical groups (cardiac disease, aortic disease or no findings/study patient). We used SPSS v 22 (SPSS Inc., Chicago, IL, USA) for all analyses.

\section{Results}

\section{General characteristics of the patients}

During the 18-month study period, 149 consecutive patients underwent 151 MRI scans. None denied participation. Seven cases were excluded due to repeat MRI scans in patients already included $(n=2)$, MRI scans not available $(n=2)$, INL could not be identified $(n=2)$, or unavailable case report form $(n=1)$. Table 1 displays clinical characteristics of the 144 patients enrolled.

\section{The structures beneath the centre of sternum}

We described the presence of all blood-filled structures beneath the centre of sternum in the INL image. The LVOT/AV/aortic root was present in almost half (46\%)
Table 1 Patient characteristics $(n=144)$

\begin{tabular}{ll}
\hline Age (years) & $51.8 \pm 17.2$ \\
\hline Males & $110(76 \%)$ \\
Height $(\mathrm{cm})$ & $177.5 \pm 9.0$ \\
Weight $(\mathrm{kg})$ & $81.0 \pm 14.1$ \\
$\mathrm{BMl}\left(\mathrm{kg} / \mathrm{m}^{2}\right)$ & $25.6 \pm 3.6$ \\
Clinical groups: & \\
Cardiac disease & $74(51 \%)$ \\
Aortic disease & $13(9 \%)$ \\
No findings/study patient & $57(40 \%)$
\end{tabular}

Nonpercent values are \pm SDs

$B M I$ body mass index

of patients with cardiac disease vs. $19 \%$ of patients with no findings/study patients $(p=0.006)$ (Fig. 2$)$. The left and right ventricle was present in 2 and $48 \%$ of all patients, respectively. Details are described in Additional file 1 . The most frequent dominating structure in all patients was the left atrium (41\%) or the right ventricle (31\%). The left ventricle was not the dominating structure in any patient.

\section{Anterior-posterior diameters}

Mean (SD) AP EXTERNAL for males and females were 24.5 (2.2) and $21.6(2.4) \mathrm{cm}$, respectively. A compression depth of 5-6 cm would correspond to a reduction in $\mathrm{AP}_{\text {EXTERNAL }}$ for males and females of $20-24 \%$ and $23-$ $28 \%$, respectively. $\mathrm{AP}_{\mathrm{BLOOD}}$ for males was $6.5(1.8) \mathrm{cm}$ and for females $4.7(2.1) \mathrm{cm}$ with $\mathrm{AP}_{\mathrm{BLOOD}} / \mathrm{AP}_{\text {EXTERNAL }}$ ratio of .26 and .22 respectively. Unadjusted and adjusted differences between males and females are displayed in Table 2. Gender and age were significant explanatory fac-

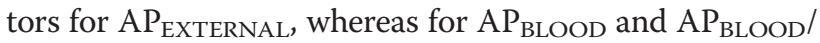

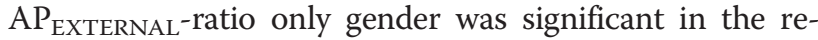
gression analysis. Figure 3 displays a scatter plot of $\mathrm{AP}_{\mathrm{EX}}$ TERNAL and $\mathrm{AP}_{\mathrm{BLOOD}}$ at the internipple line level, divided into gender.

\section{Hypothetical optimal compression point (OCP)}

Figure 4 displays $\mathrm{OCP}$ for all patients and clinical groups. Mean (SD) OCP was found $3.2(1.1) \mathrm{cm}$ to the left and 1.6 (2.1) $\mathrm{cm}$ caudal to origo. There were no significant differences between clinical groups, but a tendency to larger caudal displacement of OCP in the clinical groups with pathological findings (cardiac disease and aortic disease).

\section{Discussion}

In 144 patients referred to cardiovascular MRI, the relationship between intrathoracic cardiovascular structures and detectable surface landmarks for chest compression hand placement varied significantly. We found that left ventricle was rarely present beneath centre of sternum while the left ventricular outflow tract (LVOT), aortic 


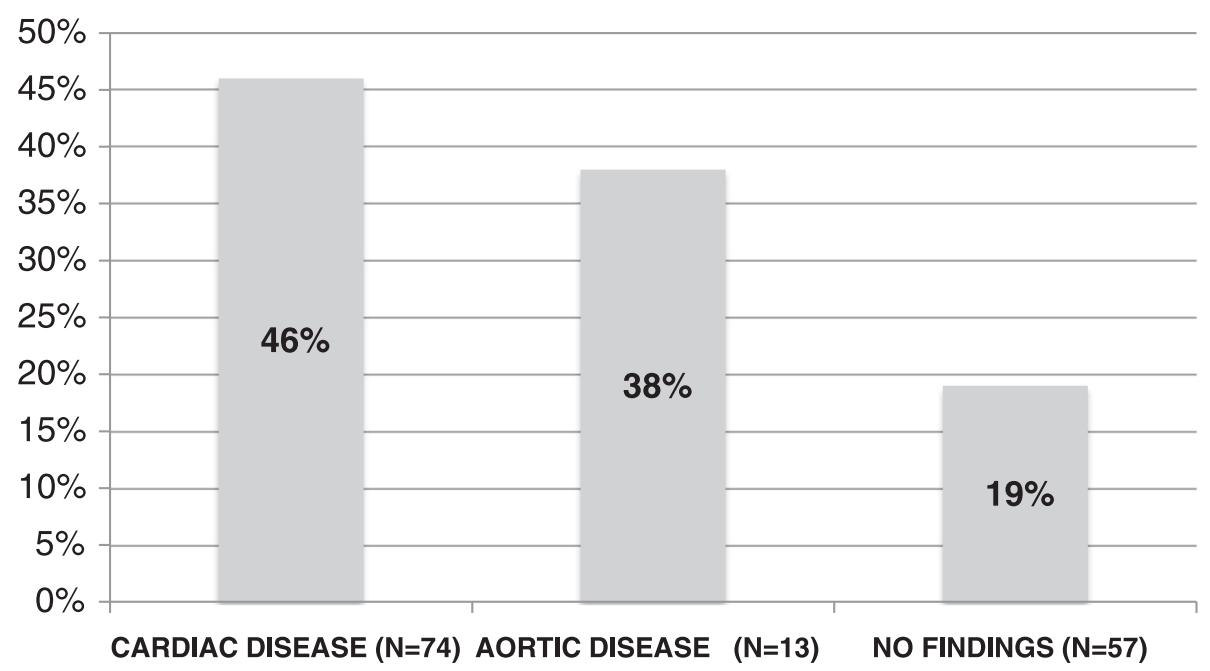

Fig. 2 Presence of LVOT/AV/aortic root beneath the centre of sternum at the internipple line level divided into clinical groups. Abbreviations: LVOT/AV/ aortic root, left ventricular outflow tract/aortic valve/aortic root

valve, or aortic root was present in almost half of the patients with cardiac disease.

External chest compressions have been integral to CPR since first described by Kouwenhoven in 1960 [8]. Recommendations for hand position have changed over the years. ILCOR recommends placing the hands on the lower half of the sternum. ERC/ILCOR concluded in 2010 that the internipple line (INL) was not a reliable landmark for hand placement based on diverging results from studies of CT-scans and simulations on real patients. Shin et al. found the ascending aorta, the root of aorta or the LVOT beneath INL in about $80 \%$ of the patients and concluded that compressing the sternum more caudally might be more effective [3]. However, Kusunoki et al. concluded that use of the INL for CPR might result in the compressing hand extending to the xiphoid process with organ injury as a possible consequence [9]. Additionally, the lower half of the sternum might not be readily understandable for a layperson while "in the middle of the chest, between the nipples" is easily understandable. Birkenes et al. found that the use of INL in pre-arrival telephone instructions to rescuers resulted in less caudal hand placements and none in the abdominal region [10].

In the present study the fraction of patients with LVOT/AV/aortic root was lower than found by Shin et al. [3], but still occurred in almost half the patients with cardiac disease, less in the other clinical groups. Patients in both studies were supine with arms along the sides. The LV and RV were present beneath the centre of sternum in 3 and $41 \%$ in patients with cardiac disease, respectively; in contrast to Shin et al. who found LV present in one-fifth in their combined group. Papadimitriou et al. used CT scans to investigate the relationship between cardiac structures and ribs and found that the occurrence of cardiac chambers under the lower part of the sternum (ribs 4-6) was very high [11], almost $100 \%$ for RV and LV. They concluded that this was a reasonable position for hand placement during chest compressions. In contrast to our study they noted all structures that appeared in the CT axial scan. We chose to identify only structures directly beneath the centre of sternum, although other structures were present in the INL image. This can partly explain the diverging results between their study and the present study.

Forward blood flow is provided by direct compression of the cardiac ventricles and intra-thoracic pressure fluctuations. Compressing the LVOT might reduce the positive effect of compressing the ventricles, and asymmetrical compression of the ventricles $(\mathrm{RV}>\mathrm{LV})$ is an unknown factor. The combination of these might explain the lack of effect of chest compressions sometimes observed clinically, and the heterogeneity observed in a clinical pilot study of changing hand positions [12]. In that study, where endtidal $\mathrm{CO} 2(\mathrm{EtCO} 2)$ was used as an indication of cardiac output during CPR, there were no significant differences in $\mathrm{EtCO} 2$ with altered compression points. Direct observations with transoesophageal echocardiography (TEE) by Hwang et al. during resuscitation showed that the outflow of the left ventricle is affected resulting in varying degrees of narrowing in the LVOT and/or the aortic root [4]. They also suggested that the technical limitations of TEE preclude its use during routine CPR. Further, Tømte et al. used TEE in anaesthetized domestic pigs and revealed the presence of asymmetrical compression in several animals despite the same sternal piston positioning and the same placement of the pigs with prevention of lateral displacement [13].

To our knowledge, few others have hypothesized an optimal compression point based on the cardiovascular 


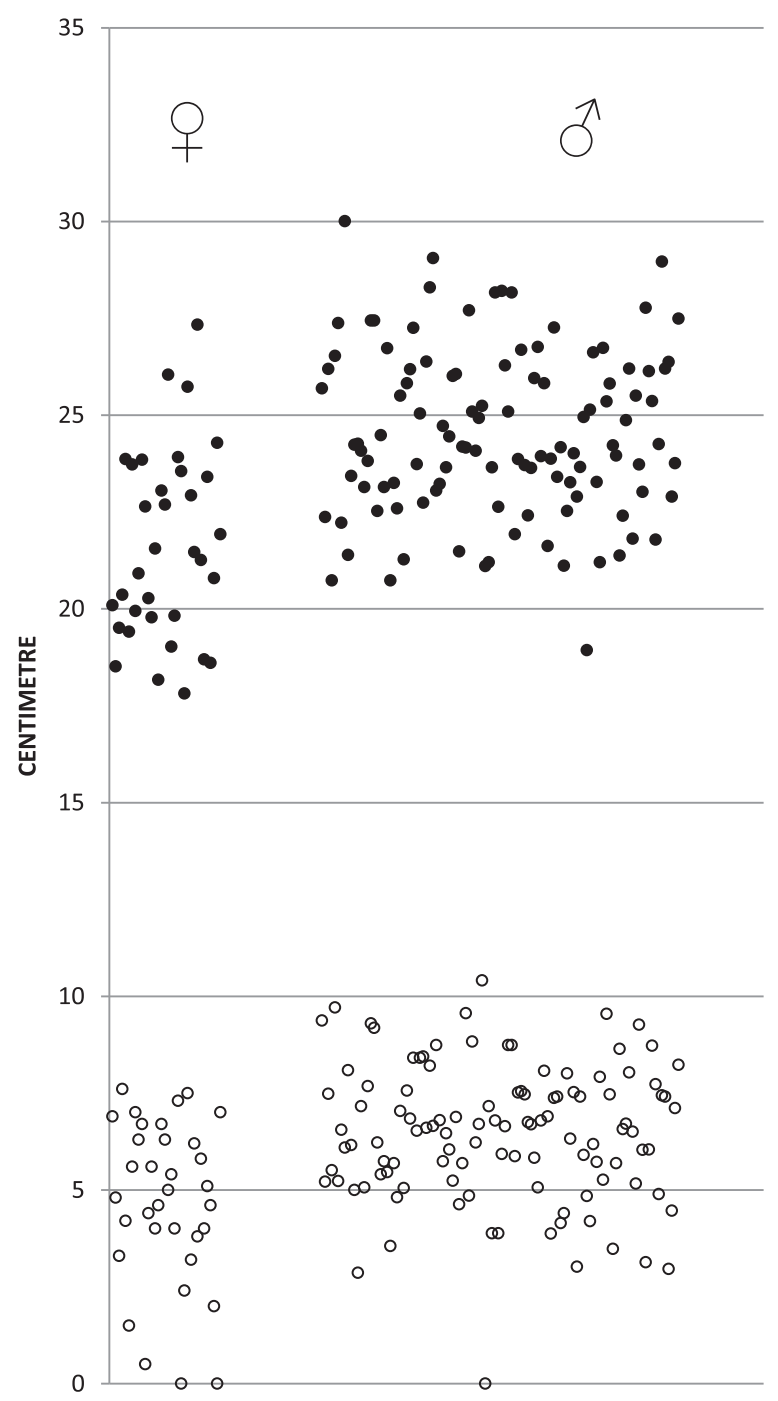

Fig. 3 Scatter plot of $A P_{\text {EXTERNAL }}$ and $A P_{B L O O D}$ at the internipple line level, divided into gender (left - females, right - males). Each patient is represented by one $A P_{\text {EXTERNAL Symbol (filled) and one } A P_{B L O O D}}$ symbol (open). APBLOOD, Anterior-posterior diameter of blood-filled structures; APEXTERNAL, external anterior-posterior diameter

Table 2 The unadjusted and adjusted differences between males and females in AP EXTERNAL, $\mathrm{AP}_{\text {BLOOD }}$ and the ratio between them

\begin{tabular}{|c|c|c|c|}
\hline & $\begin{array}{l}\text { Mean difference } \\
(95 \% \mathrm{Cl})\end{array}$ & $\begin{array}{l}\text { Difference } \\
\text { (Adj.) }^{\mathrm{a}}\end{array}$ & $\begin{array}{l}P \text {-value } \\
\text { (regression analysis) }\end{array}$ \\
\hline \multicolumn{4}{|l|}{$\overline{A P_{\text {EXTERNAL }}}$} \\
\hline Gender & $2.9(2.0,3.8)$ & $2.1(1.1,3.2)$ & $<0.001$ \\
\hline \multicolumn{4}{|l|}{$\mathrm{AP}_{\mathrm{BLOOD}}$} \\
\hline Gender & $1.8(1.1,2.5)$ & $2.0(1.0,2.9)$ & $<0.001$ \\
\hline \multicolumn{4}{|l|}{$\begin{array}{l}\text { AP }_{\text {BLOOD }} / \\
\text { AP EXTERNAL }^{2}\end{array}$} \\
\hline Gender & $0.05(0.01,0.08)$ & $0.06(0.02,0.10)$ & 0.003 \\
\hline
\end{tabular}

${ }^{\mathrm{a}}$ Adjusted for height, age and clinical group structures. We found a hypothesis generating optimal compression point (OCP) based on maximum compressible left and right ventricle to be to the left and caudal to the centre of sternum at the INL level. Shin et al. argued for a more caudal compression point [3], and in children the best compression point has been found to be the lower third of sternum, caudal to the INL [14]. If the present hypothesis is correct, in a majority of patients the optimal compression point is both to the left of the midline and slightly caudal to the INL. As the LVOT anatomically, in a normal setting, is directed rightward and cranially, this is also an argument for changing the compression point leftwards. It is not fully established how the force from chest compressions is transferred to intrathoracic structures. Pickard et al. suggested a mechanism where the sternum acts as a hinge as it is relatively fixed cranially making the caudal part of the sternum more flexible [7]. As to moving the compression point lateral to the sternum, we are concerned that compressions might not squeeze the intrathoracic structures between the sternum and the vertebral column, a concern only relevant if cardiac pump theory is the dominant blood flow mechanism. In the search for optimal hand position in an individualised CPR by professionals, we believe further research is warranted to develop a strategy when standard CPR is not successful. We found some differences between the clinical groups and we speculate that this can be further explored in clinical studies, as pre-existing cardiac disease as a broad category would be known on scene in many patients, and therapy could be changed accordingly to reduce the risk of compressing directly over the LVOT.

The recommended chest compression depth changed from 38-52 $\mathrm{mm}$ to 5-6 $\mathrm{cm}$ [2] partly based on didactic considerations and partly on extrapolation of earlier studies [15-18], but recent results questions this and has found the optimum chest compression depth to be 40-55 mm for both men and women [3, 19]. Current ERC guidelines recommend a compression depth of $5 \mathrm{~cm}$, not exceeding $6 \mathrm{~cm}$ in an average adult [1]. The present study was conducted based on guidelines from 2010. We found that compressing the recommended $5 \mathrm{~cm}$ corresponded to 20 and $23 \%$, of AP EXTERNAL for males and females respectively. This is in agreement with Pickard et al. who showed that a $4-5 \mathrm{~cm}$ reduction corresponded to approximately one-fifth of the AP diameter [7]. In children, Braga et al. found that in some age groups there would be no room for intrathoracic structures between the sternum and columna when compressing the recommended one-third of the AP diameter, and were concerned that this might be harmful [20]. 


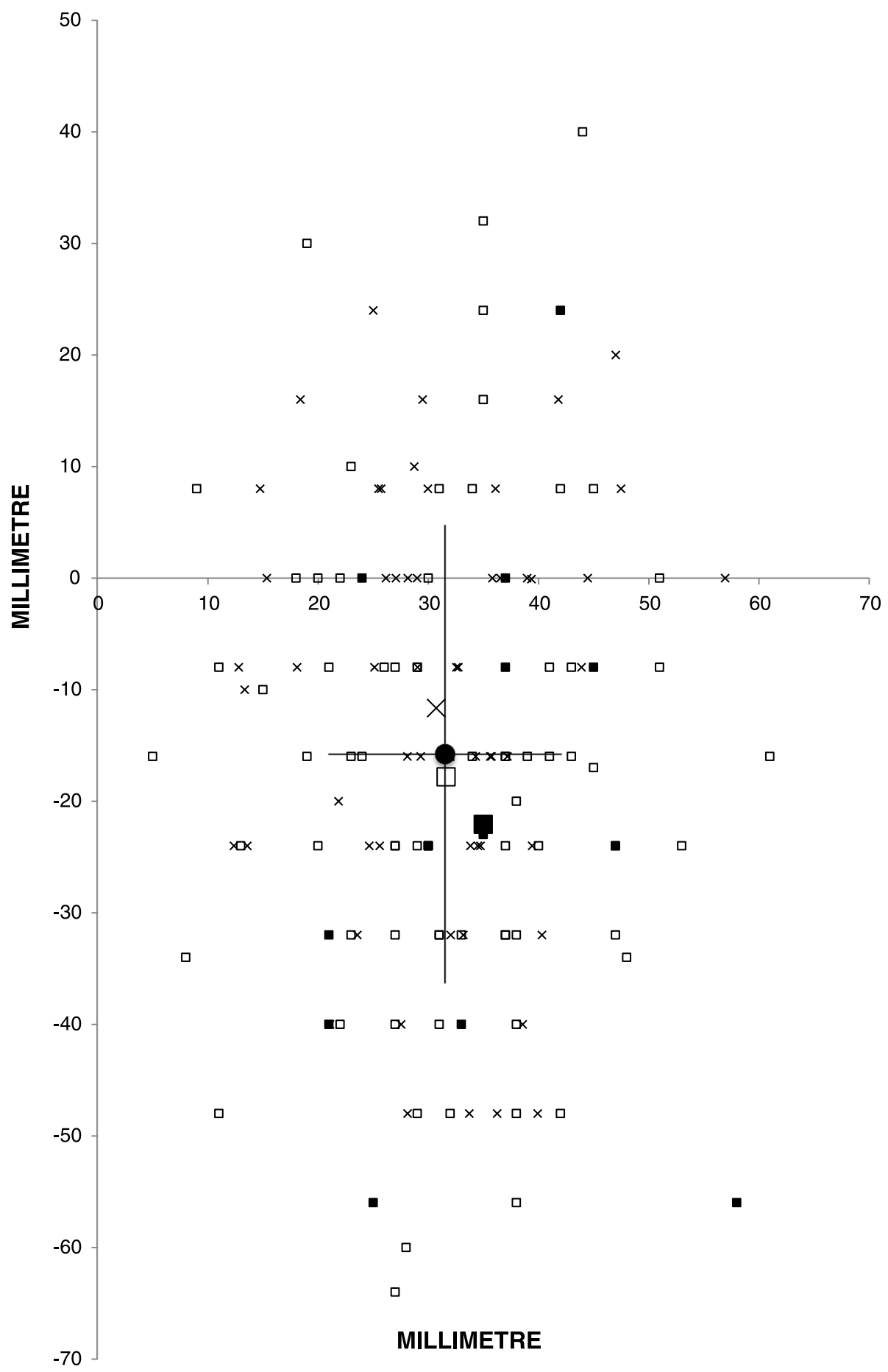

Fig. 4 Optimal compression point (OCP) in the coronal plane based on maximum compressible left and right ventricle. Origo is the centre of sternum at the internipple line level. One small symbol represents one patient and clinical groups mean values with large symbols (cardiac disease $\square$ (open square), aortic disease $\square$ (filled square), and no findings/study patient x (crosses)). Overall mean (filled circle) represented with standard deviations

If it can be assumed that it is the squeezing of bloodfilled structures that cause blood-flow, the present results indicate that 5 to $6 \mathrm{~cm}$ compressions are possible and can be valuable in most males. But, as mean
$\mathrm{AP}_{\mathrm{BLOOD}}$ for females was only $4.7 \mathrm{~cm}$ at the centre of sternum, other structures than blood might be compressed. An observational study by Hellevuo et al. suggested that a compression depth of more than $6 \mathrm{~cm}$ in 
male patients is associated with an increased rate of injury in adults when compared with compression depths of 5-6 cm during CPR [21]. No such association was observed in female patients. Although there is little direct evidence that damage from chest compression is related to compression depth, there might not be haemodynamic benefits from compressing non-bloodfilled structures such as connective tissue and myocardium. Chest compressions and artificial ventilation during CPR might relocate intrathoracic structures. With aortography, Niemann et al. showed in a canine experimental study, that the cardiac silhouette is displaced posteriorly during chest compressions [22]. MRI survey scans were not done during CPR. However, we found only cardiac and mediastinal structures along $\mathrm{AP}_{\text {EXTERNAL }}$ (Fig. 1a). These effects might not be relevant for blood flow generated by a thoracic pump mechanism. ERC guidelines do not differentiate between gender, body size or medical history. We believe the upper limit for chest compression depths, especially in women, should be elucidated.

Limitations apply to this study. It is a prospective, observational single-centre study and thus is limited by the patient selection. While fewer females than males participated, the proportion matches the ratio for cardiac arrest victims under the age of 65 [23]. The ethnicity of patients was not noted, yet Norwegians are mostly caucasians. Our results may not be representative for other ethnicities. The survey scans used in our study were obtained without electrocardiogram gating. As the axial scans are $8-10 \mathrm{~mm}$ thick and sometimes include motion artifacts, this creates some uncertainty to our results. All measurements were done by one author, with additional aid by an experienced radiologist in $56 \%$ of the cases, but no formal interobserver variation was calculated. Structures that laid adjacent to $\mathrm{AP}_{\text {EXTERNAL }}$, but were not pierced by it (since the line was thin), have not been identified as a structure beneath the centre of sternum. This explains why $\mathrm{AP}_{\mathrm{BLOOD}}$ in some of the cases was zero. Further, chest compressions by hand or mechanical device transfer pressure to a wider area than the thin line we used for measurements. Hence, volumetric measurements would provide more accurate calculations than our method. Extrathoracic soft tissue might be compressed during CPR, affecting $\mathrm{AP}_{\text {EXTERNAL. But as }}$ our patients were lying supine, the soft tissue posteriorly is already compressed to some extent.

\section{Conclusions}

The left ventricular outflow tract/aortic valve/aortic root was found beneath the centre of sternum at the internipple line (INL) level in almost half the patients with cardiac disease, while the left ventricle was present in only $3 \%$. Recommended chest compression depths exceeded the anterior-posterior diameter of blood-filled cardiovascular structures in more than half of the females. A hypothesis generating optimal compression point was found $3.2 \mathrm{~cm}$ to the left and $1.6 \mathrm{~cm}$ caudal to the centre of sternum at the INL level. Based on our study, individualized compression point and depth could be further studied in a prospective, clinical study.

\section{Additional file}

Additional file 1: The presence of blood-filled structures beneath the centre of sternum at the internipple line level. Percentages do not sum up to 100 because several structures may be present in one patient. (DOCX $65 \mathrm{~kb})$

\section{Abbreviations}

AP: anterior-posterior; $\mathrm{AP}_{\mathrm{BLOOD}}$ : AP diameter of blood-filled structures;

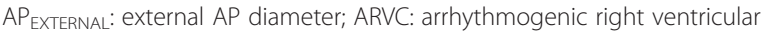
cardiomyopathy; AV: aortic valve; CMR: cardiovascular MRI; CPR: cardiopulmonary resuscitation; INL: internipple line; LV: left ventricle; LVOT: left ventricular outflow tract; OCP: optimal compression point; PV: pulmonary valve; RV: right ventricle; RVOT: right ventricular outflow tract; TEE: transoesophageal echocardiography.

\section{Competing interests}

The authors declare that they have no competing interests.

\section{Authors' contributions}

KHS and JKJ conceived and designed this study. VR collected the data and obtained patient consent. JKJ and SN planned and performed the data analysis and SN prepared the figures. KHS, JKJ and SN interpreted the data. SN drafted the manuscript. JKJ provided study supervision. All authors critically revised the manuscript and have read and approved the final manuscript.

\section{Acknowledgements}

SN received unrestricted grant support from the Laerdal Foundation. The foundation was not involved in any part of the study. In-house funding funded the other authors. We thank the Norwegian National Advisory Unit on Prehospital Emergency Medicine (NAKOS) and sonographers and co-workers at the Intervention- and sonography Unit at Oslo University Hospital.

\section{Author details}

${ }^{1}$ Department of Anaesthesiology, Oslo University Hospital, Po Box 4956 Nydalen, N-0424 Oslo, Norway. ${ }^{2}$ Department of Radiology and Nuclear Medicine and Institute of Circulation and Imaging, St Olavs University Hospital and Norwegian University of Science and Technology, Po Box 3250 Sluppen, N-7006 Trondheim, Norway. ${ }^{3}$ Intervention- and Sonography Unit, Oslo University Hospital, Po Box 4956 Nydalen, N-0424 Oslo, Norway. ${ }^{4}$ Norwegian National Advisory Unit on Prehospital Emergency Medicine (NAKOS), Oslo University Hospital and University of Oslo, Po Box 4956 Nydalen, N-0424 Oslo, Norway.

Received: 15 January 2016 Accepted: 14 April 2016 Published online: 22 April 2016

References

1. Perkins GD, Travers AH, Berg RA, Castrén M, Considine J, Escalante R, et al. Part 3: adult basic life support and automated external defibrillation: 2015 international consensus on cardiopulmonary resuscitation and emergency cardiovascular care science with treatment recommendations. Resuscitation. 2015;95:e43-69.

2. Koster RW, Sayre MR, Botha M, Cave DM, Cudnik MT, Handley AJ, et al. Part 5: adult basic life support: 2010 international consensus on cardiopulmonary resuscitation and emergency cardiovascular care science with treatment recommendations. Resuscitation. 2010;81 Suppl 1:e48-70.

3. Shin J, Rhee JE, Kim K. Is the inter-nipple line the correct hand position for effective chest compression in adult cardiopulmonary resuscitation? Resuscitation. 2007;75:305-10. 
4. Hwang SO, Zhao PG, Choi HJ, Park KH, Cha KC, Park SM, et al. Compression of the left ventricular outflow tract during cardiopulmonary resuscitation. Acad Emerg Med. 2009;16:928-33.

5. Cha KC, Kim YJ, Shin HJ, Cha YS, Kim H, Lee KH, et al. Optimal position for external chest compression during cardiopulmonary resuscitation: an analysis based on chest $\mathrm{CT}$ in patients resuscitated from cardiac arrest. Emerg Med J. 2013;30:615-9.

6. Perkins GD, Handley AJ, Koster RW, Castrén M, Smyth MA, Olasveengen T, et al. European resuscitation council guidelines for resuscitation 2015: section 2. Adult basic life support and automated external defibrillation. Resuscitation. 2015:95:81-99.

7. Pickard A, Darby M, Soar J. Radiological assessment of the adult chest: implications for chest compressions. Resuscitation. 2006;71:387-90.

8. Kouwenhoven WB, Jude JR, Knickerbocker GG. Closed-chest cardiac massage. JAMA. 1960;173:1064-7.

9. Kusunoki S, Tanigawa K, Kondo T, Kawamoto M, Yuge O. Safety of the internipple line hand position landmark for chest compression. Resuscitation. 2009;80:1175-80

10. Birkenes TS, Myklebust $\mathrm{H}$, Kramer-Johansen J. New pre-arrival instructions can avoid abdominal hand placement for chest compressions. Scandinavian Journal of Trauma, Resuscitation and Emergency Medicine. Scand I Trauma Resusc Emerg Med. 2013;21:1.

11. Papadimitriou P, Chalkias A, Mastrokostopoulos A, Kapniari I, Xanthos T. Anatomical structures underneath the sternum in healthy adults and implications for chest compressions. Am J Emerg Med. 2013;31:549-55.

12. Qvigstad E, Kramer-Johansen J, Tømte Ø, Skålhegg T, Sørensen $\varnothing$, Sunde K, et al. Clinical pilot study of different hand positions during manual chest compressions monitored with capnography. Resuscitation. 2013;84:1203-7.

13. Tømte Ø, Sjaastad I, Wik L, Kuzovlev A, Eriksen M, Norseng PA, et al. Discriminating the effect of accelerated compression from accelerated decompression during high-impulse CPR in a porcine model of cardiac arrest. European Resuscitation Council Guidelines for Resuscitation 2010 Section 2. Adult basic life support and use of automated external defibrillators. 2010;81:488-92.

14. Orlowski JP. Optimum position for external cardiac compression in infants and young children. Ann Emerg Med. 1986;15:667-73.

15. Handley AJ, Koster R, Monsieurs K, Perkins GD, Davies S, Bossaert L, et al. European resuscitation council guidelines for resuscitation 2005. Section 2. Adult basic life support and use of automated external defibrillators. Resuscitation. 2005;67 Suppl 1:S7-23.

16. Koster RW, Baubin MA, Bossaert LL, Caballero A, Cassan P, Castrén M, et al. European resuscitation council guidelines for resuscitation 2010 section 2. Adult basic life support and use of automated external defibrillators. 2010; 81:1277-92. Available from: http://eutils.ncbi.nlm.nih.gov/entrez/eutils/elink. fcgi?dbfrom=pubmed\&id=20956051\&retmode=ref\&cmd=prlinks

17. Kramer-Johansen J, Myklebust H, Wik L, Fellows B, Svensson L, Sørebø H, et al. Quality of out-of-hospital cardiopulmonary resuscitation with real time automated feedback: a prospective interventional study. Resuscitation. 2006; 71:283-92.

18. Bohn A, Weber TP, Wecker S, Harding U, Osada N, Van Aken H, et al. The addition of voice prompts to audiovisual feedback and debriefing does not modify CPR quality or outcomes in out of hospital cardiac arrest-a prospective, randomized trial. Resuscitation. 2011;82:257-62.

19. Stiell IG, Brown SP, Nichol G, Cheskes S, Vaillancourt C, Callaway CW, et al. What is the optimal chest compression depth during out-of-hospital cardiac arrest resuscitation of adult patients? Circulation. 2014;130:1962-70.

20. Braga MS, Dominguez TE, Pollock AN, Niles D, Meyer A, Myklebust $H$, et al. Estimation of optimal CPR chest compression depth in children by using computer tomography. Pediatrics. 2009;124:e69-74.

21. Hellevuo H, Sainio M, Nevalainen R, Huhtala H, Olkkola KT, Tenhunen J, et al. Deeper chest compression - more complications for cardiac arrest patients? Resuscitation. 2013;84:760-5.

22. Niemann JT, Rosborough JP, Hausknecht M, Garner D, Criley JM. Pressuresynchronized cineangiography during experimental cardiopulmonary resuscitation. Circulation. 1981;64:985-91.

23. Lund-Kordahl I, Olasveengen TM, Lorem T, Samdal M, Wik L, Sunde K. Improving outcome after out-of-hospital cardiac arrest by strengthening weak links of the local Chain of Survival; quality of advanced life support and post-resuscitation care. Resuscitation. 2010;81:422-6.

\section{Submit your next manuscript to BioMed Central and we will help you at every step:}

- We accept pre-submission inquiries

- Our selector tool helps you to find the most relevant journal

- We provide round the clock customer support

- Convenient online submission

- Thorough peer review

- Inclusion in PubMed and all major indexing services

- Maximum visibility for your research

Submit your manuscript at www.biomedcentral.com/submit
() BioMed Central 